\title{
Comparisons of PI and ANN controllers for shunt HPF based on STF-PQ Algorithm under distorted grid voltage
}

\author{
Mohamed Asghaiyer Omran', Izzeldin. I. Ibrahim², Abu Zaharin Ahmad ${ }^{3}$, Mohamed Salem ${ }^{4}$, \\ Mohamad Milood Almelian ${ }^{5}$, Awang Jusoh ${ }^{6}$, Tole Sutikno ${ }^{7}$ \\ 1,2,3,5 Faculty of Electrical and Electronics Engineering, Universiti Malaysia Pahang, Malaysia \\ ${ }^{4}$ School of Electrical and Electronic Engineering, Universiti Sains Malaysia, Malaysia \\ ${ }^{6}$ Faculty of Electrical Engineering, Universiti Teknologi Malaysia, Malaysia \\ ${ }^{7}$ Department of Electrical Engineering, Universitas Ahmad Dahlan, Indonesia
}

\begin{tabular}{l}
\hline Article Info \\
\hline Article history: \\
Received Nov18, 2018 \\
Revised Feb 22, 2019 \\
Accepted Mar 20, 2019 \\
\hline Keywords: \\
ANN controller \\
PI controller \\
Reactive power \\
Self-tuning filter \\
Shunt hybrid filter \\
\hline
\end{tabular}

\begin{abstract}
This paper proposes a shunt hybrid power filter (HPF) for harmonic currents and reactive power compensation under a distorted voltage and in a polluted environment. For this purpose, the reference current of the shunt HPF is computed based on the instantaneous reactive power (p-q) theory with selftuning filter (STF). In order to adjust the dc voltage as a reference value, PI and ANN controllers have been utilized. Moreover, the system has been implemented and simulated in a MATLAB-SIMULINK platform, and selected results are presented. Therefore, the results verified the good dynamic performance, transient stability and strong robustness of the ANN controller. Furthermore, the shunt HAPF with ANN controller has been found to be in agreement with the IEEE 519-1992 standard recommendations on harmonic levels.
\end{abstract}

Copyright (C) 2019 Institute of Advanced Engineering and Science. All rights reserved.

\section{Corresponding Author:}

Mohamed Asghaiyer Omran,

Faculty of Electrical and Electronics Engineering,

Universiti Malaysia Pahang,

Pekan 26600, Pahang, Malaysia.

Email: omranmohamed346@yahoo.com

\section{INTRODUCTION}

In power systems, harmonic distortion is a major power quality problem. Harmonics are often generated in the power systems when there are nonlinear loads such as a controlled rectifier, inductive loads, and single-phase or three-phase un-controlled diode rectifiers [1]. Harmonics in the power source results in the heating up of the transformers, power factor reduction, electromagnetic interference(EMI), and damage to power electronics device [2-5]. It is, therefore, necessary to ensure that the dominant harmonics is reduced to less than $5 \%$ as stipulated by the international standards such as IEC1000-3-2, IEC1000-3-4, and IEEE519-1992 [6]. For an efficient power system operation, it is compulsory to minimize the power systems' harmonic contents and as such, various tools for the regulation of harmonics such as the conventional passive power filters (PPF), hybrid power filters (HPF), and active power filters (APF) have been developed [7]. However, the HPFs have been the most appropriate solutions for power quality improvement but the development of a hybrid filter through the combination of both PPF and APF can be a better solution since the advantages of the seed filters (i.e. the reduction of the active converters' VA rating to ensure a minimized overall cost, electromagnetic interference and losses) will be retained [8]. Several control strategies have been developed for the determination of the reactive and harmonic load current components. Such strategies include the $\mathrm{p}-\mathrm{q}$ theory and the SRF which have performed equally although their differences are evident when working under unbalanced and distorted AC voltages [9-12]. 
The self-tuning filters (STF) classical PQ theory served as the basis in this paper for the generation of the shunt HAPF control reference current under distorted voltage conditions. The STF is deployed for the direct extraction of the fundamental components from electrical signals under distorted voltage conditions in the $\alpha-\beta$ reference frame. The major component of the APF operation is the controller and has attracted numerous research attention recently[13-15]. The harmonic current and DC voltage of the shunt HAPF have often been controlled using the conventional current and voltage controllers; however, these conventional techniques require a precise linear mathematical system modeling, and this is difficult to achieve under different parameters, load disturbances, and non-linearity. These limitations can be addressed by deploying ANN controllers [10]; hence, in this paper, the backpropagation network (ANN) controller schemes are proposed for the regulation of DC-link voltage and harmonic current to improve the performances of shunt HAPF.

\section{SELF-TUNING FILTER BASED ON INSTANTANEOUS ACTIVE AND REACTIVE POWER (PQ) THEORY METHOD}

The most significant aspect of this advanced control is the self-tuning filter; it annuls the contribution of the PLL to the observed disturbances and efficiently filters the currents in the $\alpha-\beta$ axis. Based on Figure 1 [16], the output signals can be represented by:

$$
\begin{aligned}
& \widehat{X_{\alpha}}(s)=K / S\left[X_{\alpha}(S)-\widehat{X_{\alpha}}(s)\right]-\omega_{c} / s * \widehat{X_{\beta}}(s) \\
& \widehat{X_{\beta}}(s)=K / S\left[X_{\beta}(S)-\widehat{X_{\alpha \beta}}(s)\right]-\omega_{c} / s * \widehat{X_{\alpha}}(s)
\end{aligned}
$$

Thus, the STF can be used for the retrieval of the basic components from the distorted electrical signals without amplitude changes or phase delay.

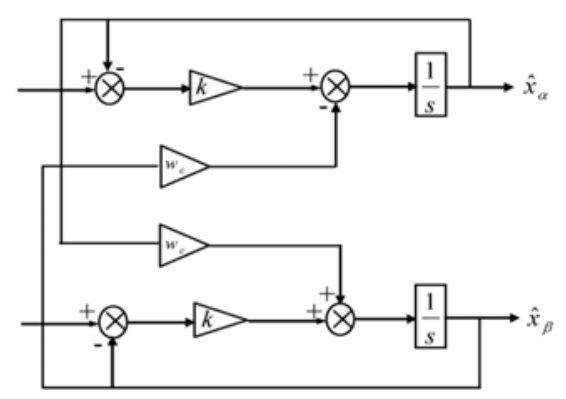

Figure 1. Self-tuning filter

The PQ theory applies Clarke transformation to currents and voltages from the 3-phase to a 2-phase system', which defines the instantaneous powers. The 3 -phase load current is converted into $\alpha-\beta$ using, respectively [17].

$$
\left[\begin{array}{l}
\mathrm{I}_{\alpha} \\
\mathrm{I}_{\beta}
\end{array}\right]=\left[\mathrm{T}_{\mathrm{M}}\right]\left[\begin{array}{c}
\mathrm{I}_{\mathrm{S}}^{\mathrm{A}} \\
\mathrm{I}_{\mathrm{S}}^{\mathrm{B}} \\
\mathrm{I}_{\mathrm{S}}^{\mathrm{C}}
\end{array}\right]
$$

Where $\mathrm{T}_{\mathrm{M}}$ is the transformation matrix as

$$
\sqrt{2 / 3}\left[\begin{array}{ccc}
1 & 1 / 2 & -1 / 2 \\
0 & \sqrt{3} / 2 & -\sqrt{3} / 2
\end{array}\right]
$$

Evidently, the currents in the $\alpha-\beta$ axis can be reduced to their DC and AC components respectively by: 


$$
\begin{aligned}
& \mathrm{I}_{\alpha}=\widehat{I_{\alpha}}+\ddot{I}_{\alpha} \\
& \mathrm{I}_{\beta}=\widetilde{\mathrm{I}}_{\beta}+\ddot{I}_{\beta}
\end{aligned}
$$

The STF is then used to directly extract the basic currents' components at the pulsation in the $\alpha-\beta$ axis before subtracting the STFs' input signals from the corresponding outputs to compute the load currents' $\alpha-\beta$ harmonic components. The alternating components, $\ddot{I}_{\alpha}$ and $\ddot{I}_{\beta}$ which corresponds to the load currents' harmonic components in the stationary reference frame are the output signals. Regarding the source voltage, the 3 voltages $V_{S}^{A}, V_{S}^{B}$ and $V_{S}^{C}$ are transformed to $\alpha-\beta$ reference frame thus:

$$
\left[\begin{array}{l}
\mathrm{V}_{\alpha} \\
\mathrm{V}_{\beta}
\end{array}\right]=\sqrt{2 / 3}\left[\mathrm{~T}_{\mathrm{M}}\right]\left[\begin{array}{l}
\mathrm{V}_{\mathrm{S}}^{\mathrm{A}} \\
\mathrm{V}_{\mathrm{S}}^{\mathrm{B}} \\
\mathrm{V}_{\mathrm{S}}^{\mathrm{C}}
\end{array}\right]
$$

The active and reactive instantaneous power 'p' and 'q' are given by

$$
\begin{aligned}
& \mathrm{P}=\widehat{\mathrm{P}}+\dddot{\mathrm{P}}, \mathrm{P}=\mathrm{I}_{\alpha} * \widehat{V_{\alpha}}+\mathrm{I}_{\beta} * \widehat{V_{\beta}} \\
& \mathrm{Q}=\widehat{\mathrm{Q}}+\dddot{\mathrm{Q}} \cdot \mathrm{Q}=\mathrm{I}_{\beta} * \widehat{V_{\alpha}}+\mathrm{I}_{\alpha} * \widehat{V_{\beta}}
\end{aligned}
$$

Where $\widehat{P}, \widehat{Q}=$ fundamental components, $\dddot{P}, \dddot{Q}=$ alternative components. $\dddot{P}, \dddot{Q}$ (Power components) which relates to the $\alpha-\beta$ of the same currents and voltages can be expressed thus:

$$
\left[\begin{array}{l}
\dddot{P} \\
\dddot{Q}
\end{array}\right]=\left[\begin{array}{cc}
\widehat{V_{\alpha}} & \widehat{V_{\beta}} \\
-\widehat{V}_{\beta} & \widehat{V_{\alpha}}
\end{array}\right]
$$

Having added the required active power for the regulation of the DC bus voltage $\mathrm{P}_{\mathrm{C}}$ to the $\mathrm{AC}$ component of the instantaneous real power $\dddot{\mathrm{P}}$, the filter reference current in the A-B-C coordinates are then, defined by:

$$
\left[\begin{array}{l}
\mathrm{I}_{\mathrm{A}}^{*} \\
\mathrm{I}_{\mathrm{B}}^{*} \\
\mathrm{I}_{\mathrm{C}}^{*}
\end{array}\right]=\sqrt{2} / 3\left[\begin{array}{cc}
1 & 0 \\
1 / 2 & \sqrt{3} / 2 \\
-1 / 2 & -\sqrt{3} /{ }_{2}
\end{array}\right]
$$

The HPF controlling framework is schematically depicted in Figure 2. The feedback signals are detected from the AC source, the load currents, and the DC bus voltages [7]. The (3) was used to convert the 3 -phase currents from the $(a-b-c)$ phases to the $(\alpha-\beta)$ static reference phase currents $i \alpha$ and i $\beta$.

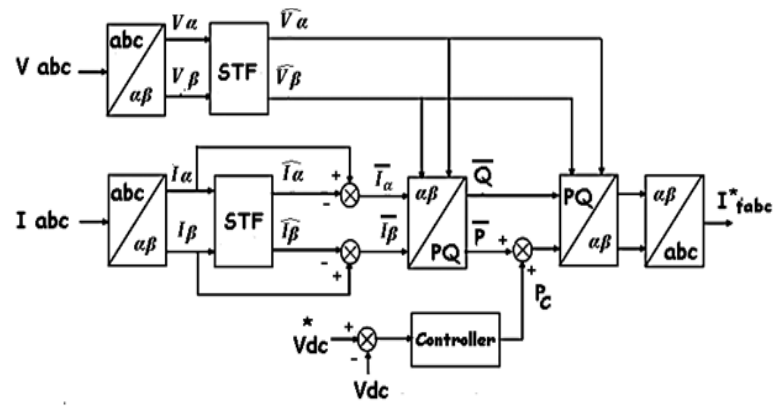

Figure 2. Control algorithm of HPF

Chronologically, a research can be explained thus: research (design, procedure (as in algorithms and pseudocodes)), data acquisition and data testing [1,7]. Each stage of a research should be described with the supporting references for such description to be scientifically acceptable [6,8]. 


\section{PI DC CAPACITOR VOLTAGE CONTROLLER}

There is a need to deal with a little measure of power streaming into DC capacitor to control DC bus voltage, consequently compensating for the conduction and exchange misfortunes. There is no need for the DC link voltage control circle to be as quick as when it responds to the relentless state working condition. The real DC interface voltage is contrasted while the voltage is connected to a PI controller via a link DC[18]. For the maintenance of the DC-link voltage at the settled reference state, a specific real power measure is required by the DC-connect capacitor; this power measure directly reflects the variation between the real and reference voltages. The control flag emanating from the PI controller to the direct DC interface voltage can be communicated as [1]:

$$
\mathrm{Pdc}=\mathrm{kp}(\mathrm{Vdcref}-\mathrm{Vdc}) \widehat{+\mathrm{Kl}} \int(\mathrm{Vdcref}-\mathrm{Vdc}) \mathrm{dt}
$$

where $\mathrm{Kp}=$ PI controllers' proportional gain, $\mathrm{Ki}=$ PI controllers' integral gain.

An expansion of the proportional gain $(\mathrm{Kp})$ minimizes the increase in steady-state error and time but can cause an increased overshoot and settling time. Similarly, an increase of the necessary pick up (Ki) reduces the relentless state mistake but can lead to overshoot and settling time. Figure 3 showed the schematic representation of PI controller.

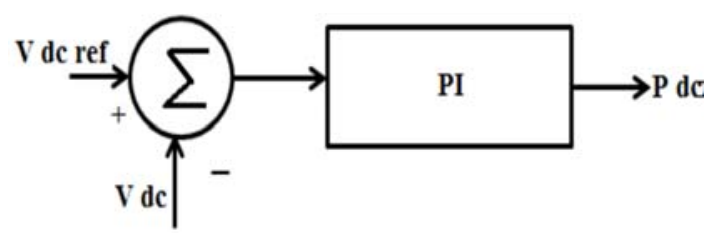

Figure 3. A schematic depiction of the PI controller

\section{ANN DC CAPACITOR VOLTAGE CONTROLLER}

The diagram of an ANN controller is depicted in Figure 4. An ANN controller consisting of 3 neuron layers (input, hidden, and output) was used in this control system. There are 3 inputs (V1, V2, $\mathrm{V} 3$ ) and 3 outputs $(\mathrm{V} 1 *, \mathrm{~V} 2 *, \mathrm{~V} 3 *)$ in the ANN controller. The ANN output passes through a comparator and is matched with a carrier signal prior to its application to the PWM generator as a reference variable. The ANN is trained by varying the weights $\mathrm{Wij}$ and the biases $\mathrm{Bj}$, while the training criterion is considered as the ANN outputs' mean square error with a value of 0.0001 . The (13) defined the error function.

$$
J=\sum_{i=1}^{N} e(i)^{2}
$$

where $\mathrm{N}$ represents the number of output neurons, and e(i) represents the instantaneous error between the estimated and actual output values. The training of the ANN is deemed completed when $\mathrm{j}$ has a value of $<0.0001[10,19,20]$.

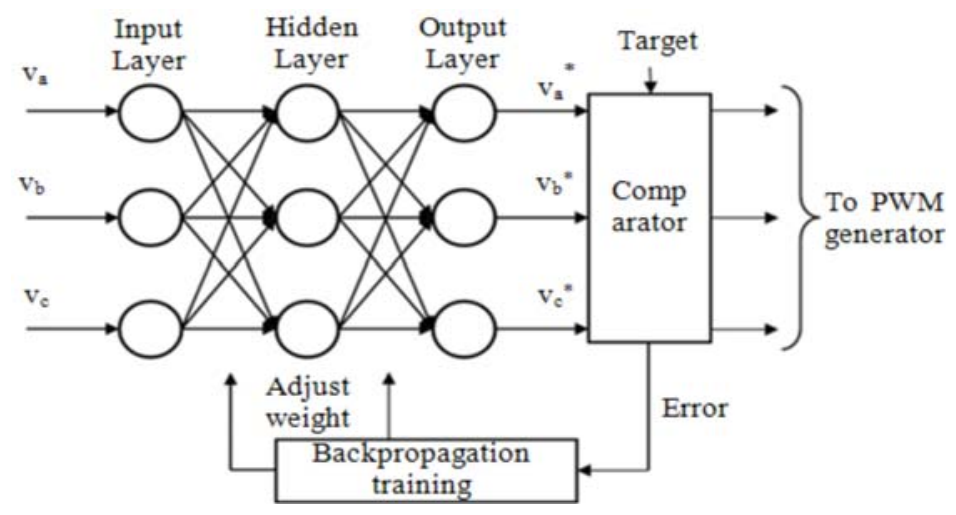

Figure 4. The block diagram of ANN controller

Int J Pow Elec \& Dri Syst, Vol. 10, No. 3, Sep 2019 : 1339 - 1346 


\section{SYSTEM PERFORMANCE}

A MATLAB/Simulink platform was used to simulate the system in order to verify the proposed method. The system parameters and their values are as follows: voltage frequency, $50 \mathrm{HZ}$; Source voltage, 240V; Resistor Rf, $0.00050 \Omega$; ; Resistor RL 1, $80 \Omega$; Inductor LL 2, $0.5 \mathrm{H}$; DC capacitor, $350 \mu \mathrm{F}$; Resistor Rs, 0. $0005 \Omega$; Inductor LL 1, $0.05 \mathrm{H}$; Inductor Lf, 0. $000075 \mathrm{H}$; inductor Ls, $0.0001 \mathrm{H}$; DC bus voltage, $450 \mathrm{~V}$; and Resistor RL 2, $120 \Omega$.

The performance of a Hybrid APF for filtering current distortions and reactive power mitigation has been examined under distortion voltage source (THD of voltage is $14.79 \%$ including $5^{\text {th }} 7^{\text {th }} 11^{\text {th }}$ are $9 \%$, $8.1 \%$ and 5.21 respectively ) with balanced nonlinear and additional loads. The THD of source current before applying a filter is high $28.53 \%$ as shown in Figure 5.

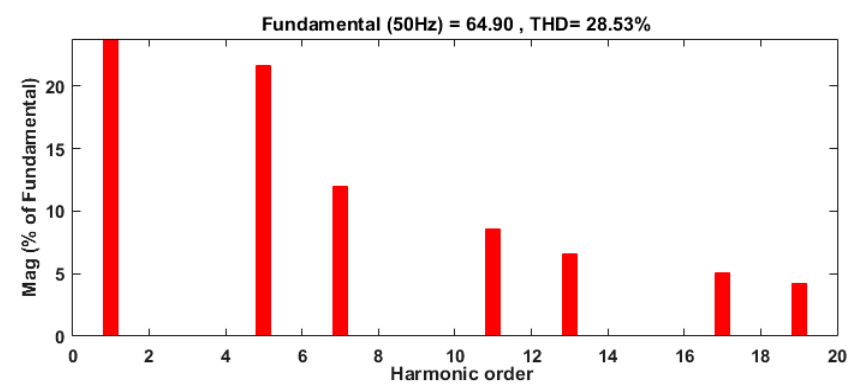

Figure 5. THD of source current without a filter

\subsection{Case 1: proportional-integral controller (PI)}

The performance of Shunt HAPFwith PI controller under distorted voltage condition has been shown in Figures 6 and 7 which provides details of the load voltage, source voltage, load current without a filter, the source current with filter, compensation filter current, DC Link voltage, THD of current.
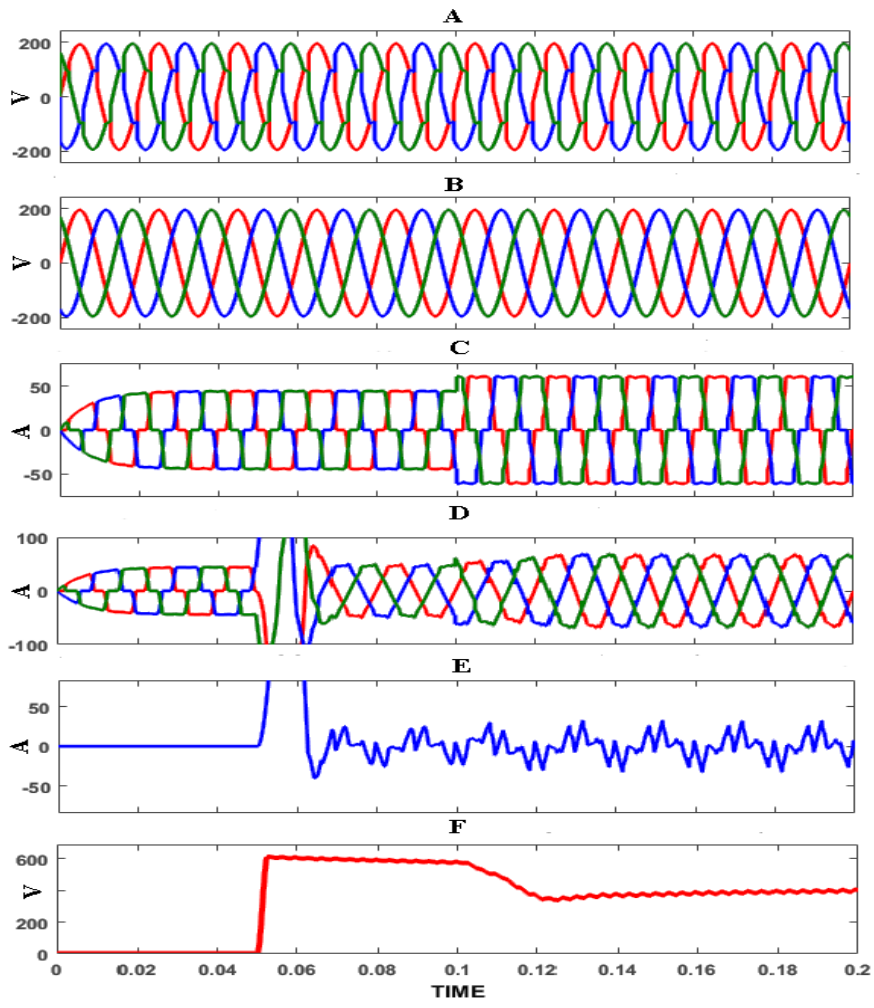

Figure 6. Shunt HAPF responses with PI controller 

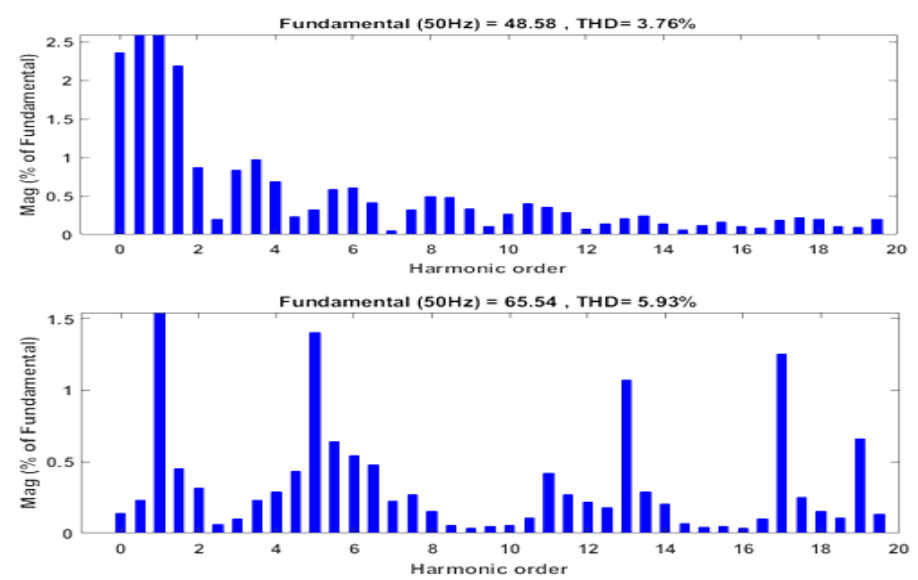

Figure 7. THD of source current with PI controller

The shunt HAPF was applying to system at $0.05 \mathrm{~s}$ and additional nonlinear load at $0.1 \mathrm{~s}$ to evaluate the performance of filter under steady and transited statuses. The source currents have been almost sinusoidal after compensation of harmonic currents. The PI controller based on shunt HAPF reduces the THD of the source current to $3.76 \%, 3.78 \%, 3.80 \%$ at period 0.05 to $0.1 \mathrm{~s}$ for phases a, b, c whereas with additional load (after $0.01 \mathrm{~s}$ ) THD is $5.93 \%, 5.87 \%, 5.91 \%$ respectively, as depicted in Table 2, besides that PI controller was unable to maintain dc bus voltage at its reference value $(540 \mathrm{v})$ after applying additional loads

\subsection{Case 2: ANN controller}

From Figures 8 and 9, it can be concluded that shunt HAPF with ANN controller contains fewer harmonics with a THD of the source current equal to $2.37 \%$ and $2.92 \%$ for both statues which are well below the permissible limit of $5 \%$ as shown in Table 2. Furthermore, ANN controller has been able to keep the DC voltage at its reference value even with transited status.

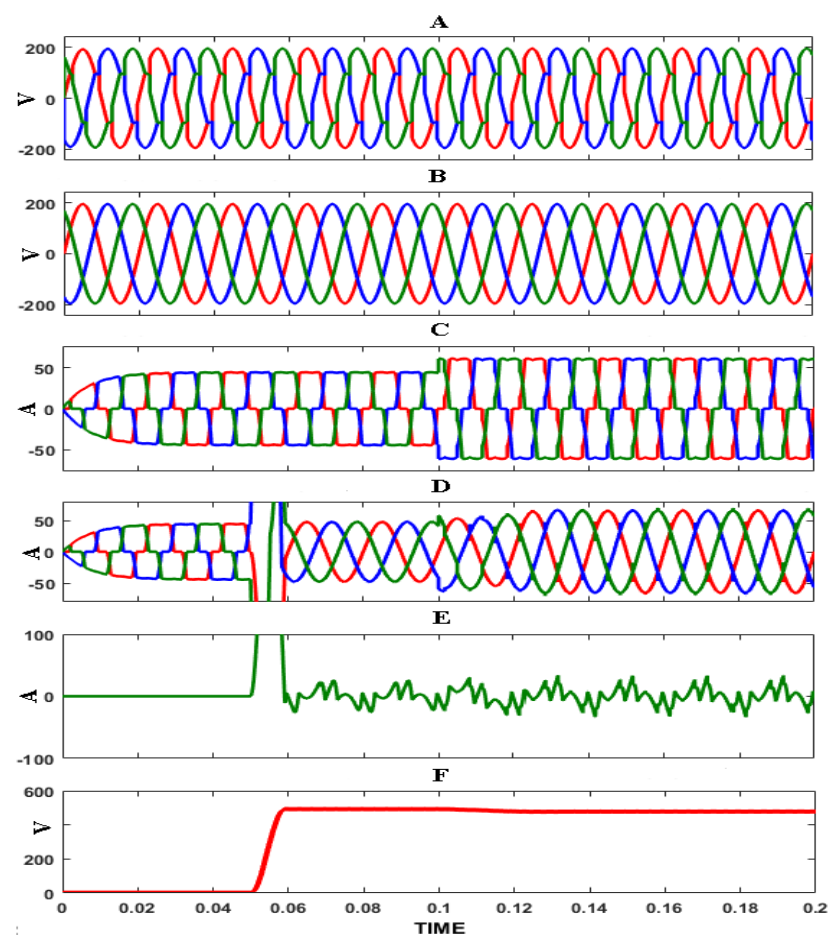

Figure 8. Shunt HAPF response with ANN controller 

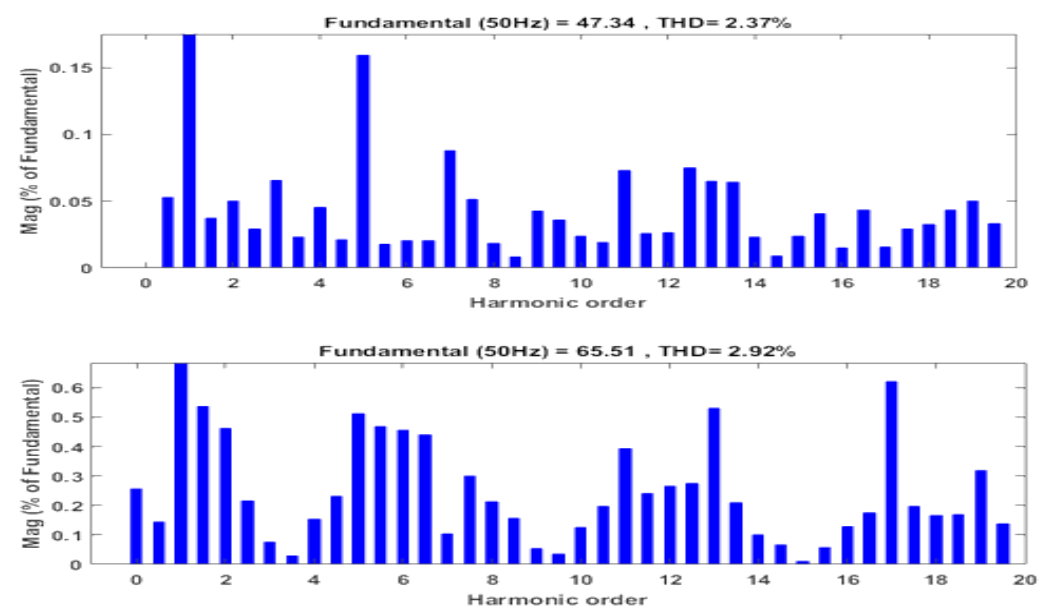

Figure 9. THD of source current with ANN controller

Table 2. Show the harmonic spectra in source current

\begin{tabular}{|c|c|c|c|c|c|c|c|c|c|c|c|c|c|c|}
\hline \multirow{2}{*}{\multicolumn{2}{|c|}{$\begin{array}{l}\text { Operations } \\
\text { Harmonics orders }\end{array}$}} & \multicolumn{6}{|c|}{ THD with Non-linear load } & \multicolumn{6}{|c|}{ THD with additional load } & \multirow{2}{*}{$\begin{array}{l}\text { THD } \\
\%\end{array}$} \\
\hline & & $5^{\text {th }}$ & $7^{\text {th }}$ & $11^{\text {th }}$ & $13^{\text {th }}$ & $15^{\text {th }}$ & $17^{t h}$ & $5^{t h}$ & $7^{t h}$ & $11^{t h}$ & $13^{\text {th }}$ & $15^{\text {th }}$ & $17^{\text {th }}$ & \\
\hline Without & A & 21.6 & 12.2 & 4.5 & 8.5 & 6.5 & 5.11 & 15.7 & 7.7 & 1.2 & 1.4 & 0.9 & 2.2 & 28.53 \\
\hline \multirow[t]{2}{*}{ filter } & $\mathrm{B}$ & 21.9 & 11.9 & 4.6 & 8.4 & 6.7 & 5.14 & 16 & 7.5 & 1.1 & 1.3 & 1 & 2.4 & 28.66 \\
\hline & $\mathrm{C}$ & 22 & 12.5 & 5 & 8.8 & 5.9 & 5 & 15.8 & 7.9 & 1.4 & 1.8 & 0.5 & 1.9 & 28.9 \\
\hline With filter & A & 1.33 & 0.05 & 0.3 & 0.21 & 0.1 & 0.18 & 1.8 & 0.7 & 0.5 & 0.9 & 0.2 & 1.1 & 5.93 \\
\hline \multirow[t]{2}{*}{$+\mathrm{PI}$} & B & 1.35 & 0.06 & 0.2 & 0.24 & 0.3 & 0.2 & 1.9 & 0.9 & 0.3 & 0.9 & 0.1 & 1.3 & 6.1 \\
\hline & $\mathrm{C}$ & 1.7 & 0.1 & 0.1 & 0.25 & 0.2 & 0.2 & 1.87 & 0.8 & 0.3 & 1 & 0.3 & 1 & 6.3 \\
\hline & A & 0.9 & 0.1 & 0.2 & 0.1 & 0 & 0.15 & 1.1 & 1 & 0.2 & 0.5 & 0.1 & 0.5 & 2.92 \\
\hline \multirow{2}{*}{+ ANN } & B & 1 & 0.1 & 0 & 0.3 & 0.1 & 0.2 & 1 & 1.2 & 0.3 & 0.5 & 0.2 & 0.5 & 2.96 \\
\hline & $\mathrm{C}$ & 1.1 & 0.2 & 0.1 & 0.5 & 0.1 & 0.2 & 1.2 & 1 & 0.3 & 0.6 & 0.2 & 0.5 & 3.01 \\
\hline
\end{tabular}

\section{CONCLUSION}

A neural network and PI controllers of dc voltage are proposed and has been implemented for the shunt HPF based on STF-p-q method in 3 phases. The performance of the proposed control strategy was evaluated for distortion source conditions with two different non-linear load types. The results revealed that the shunt HPF with ANN controller successfully kept the dc voltage constant as the reference value and reduced the grid current harmonics to around 2.37 and $2.92 \%$ for both loads. In contrast with the PI controller, the THD was minimized to 3.76 and $5.93 \%$ only. Besides, the PI controller failed to maintain the dc voltage as the reference value under both load conditions.

\section{REFERENCES}

[1] D. Soomro, M. Omran, and S. Alswed, "Design of a Shunt Active Power Filter to Mitigate the Harmonics Caused by Nonlinear Loads," ARPN Journal of Engineering and Applied Sciences, vol. 10, pp. 8774-8782, 2015

[2] M. Salem, A. Jusoh, N. R. N. Idris, H. S. Das, and I. Alhamrouni, "Resonant power converters with respect to passive storage (LC) elements and control techniques-An overview," Renewable and Sustainable Energy Reviews, vol. 91, pp. 504-520, 2018.

[3] M. Salem, A. Jusoh, N. N. Idris, T. Sutikno, and I. Abid, "ZVS Full Bridge Series Resonant Boost Converter with Series-Connected Transformer," International Journal of Power Electronics and Drive Systems, vol. 8, p. 812, 2017.

[4] M. Salem, A. Jusoh, N. R. N. Idris, T. Sutikno, and Y. M. Y. Buswig, "Phase-shifted series resonant converter with zero voltage switching turn-on and variable frequency control," International Journal of Power Electronics and Drive Systems (IJPEDS), vol. 8, pp. 1184-119, 2017.

[5] I. Alhamrouni, W. Wahab, M. Salem, A. H. N. Rahman, and L. Awalin, "Modeling of micro-grid with the consideration of total harmonic distortion analysis," Indonesian Journal of Electrical Engineering and Computer Science, vol. 15, p. 12, 2019.

[6] D. M. Soomro and M. Almelian, "Optimal design of a single tuned passive filter to mitigate harmonics in power frequency," ARPN Journal of Engineering and Applied Sciences, vol. 10, pp. 9009-9014, 2015. 
[7] M. A. Omran, I. I. Mohd, M. M. Almelian, M. A. Dawood, and M. Al-izzi, "Shunt Hybrid Active Power Filter Based on Two Compensation Strategies with PI and Fuzzy Logic Controllers," Journal of Telecommunication, Electronic and Computer Engineering (JTEC), vol. 10, pp. 75-79, 2018.

[8] M. A. Omran, I. I. Mohd, M. M. Almelian, U. U. Sheikh, and M. E. Bofares, "Investigating the ability of shunt hybrid power filter based on SRF method under non-ideal supply voltage," in IOP Conference Series: Materials Science and Engineering, 2018, p. 012083.

[9] M. M. Almelian, I. I. Mohd, M. A. Omran, and U. U. Sheikh, "Performance of unified power quality conditioner (UPQC) based on fuzzy controller for attenuating of voltage and current harmonics," in IOP Conference Series: Materials Science and Engineering, 2018, p. 012084.

[10] V. Mahajan, P. Agarwal, and H. O. Gupta, "An artificial intelligence based controller for multilevel harmonic filter," International Journal of Electrical Power \& Energy Systems, vol. 58, pp. 170-180, 2014.

[11] M. Diab, M. El-Habrouk, T. Abdelhamid, and S. Deghedie, "Survey of Active Power Filters Configurations," in 2018 IEEE International Conference on System, Computation, Automation and Networking (ICSCA), 2018, pp. 114.

[12] S. K. Prince, K. P. Panda, V. N. Kumar, and G. Panda, "Power quality enhancement in a distribution network using PSO assisted Kalman filter-Based shunt active power filter," in 2018 IEEMA Engineer Infinite Conference (eTechNxT), 2018, pp. 1-6.

[13] A. Chebabhi, K. Abdelhalim, F. M. K. Fellah, and A. Fayssal, "Self Tuning Filter and Fuzzy logic Control of Shunt Active Power Filter for Eliminates the Current Harmonics Constraints under Unbalanced Source Voltages and Loads Conditions," Journal of Power Technologies, vol. 98, pp. 1-19, 2018.

[14] Y. Dou, C. Ran, Y. Gao, Y. Li, and G. Hao, "Self-tuning WMF Kalman predictors for the multisensor descriptor systems and their convergence analysis," in 2018 37th Chinese Control Conference (CCC), 2018, pp. 4044-4049.

[15] Z. Chedjara, A. Massoum, S. Massoum, P. Wira, A. Safa, and A. Gouichiche, "A novel robust PLL algorithm applied to the control of a shunt active power filter using a self tuning filter concept," in 2018 IEEE International Conference on Industrial Technology (ICIT), 2018, pp. 1124-1131.

[16] Y. Hoon, M. Mohd Radzi, M. Hassan, and N. Mailah, "A refined self-tuning filter-based instantaneous power theory algorithm for indirect current controlled three-level inverter-based shunt active power filters under nonsinusoidal source voltage conditions," Energies, vol. 10, p. 277, 2017.

[17] Y. Hoon, M. Mohd Radzi, M. Hassan, and N. Mailah, "A self-tuning filter-based adaptive linear neuron approach for operation of three-level inverter-based shunt active power filters under non-ideal source voltage conditions," Energies, vol. 10, p. 667, 2017.

[18] I. Alhamrouni, M. Hairullah, N. Omar, M. Salem, A. Jusoh, and T. Sutikno, "Modelling and design of PID controller for voltage control of AC hybrid micro-grid," Int J Pow Elec \& Dri Syst, vol. 10, pp. 151-159, 2019.

[19] M. A. M. Radzi and N. A. Rahim, "Neural network and bandless hysteresis approach to control switched capacitor active power filter for reduction of harmonics," IEEE Transactions on Industrial Electronics, vol. 56, pp. 1477$1484,2009$.

[20] R. Martinek, J. Rzidky, R. Jaros, P. Bilik, and M. Ladrova, "Least Mean Squares and Recursive Least Squares Algorithms for Total Harmonic Distortion Reduction Using Shunt Active Power Filter Control," Energies, vol. 12, p. $1545,2019$. 